\title{
Drosophila Larvae Establish Appetitive Olfactory Memories via Mushroom Body Neurons of Embryonic Origin
}

\author{
Dennis Pauls, ${ }^{*}$ Mareike Selcho, ${ }^{*}$ Nanae Gendre, Reinhard F. Stocker, and Andreas S. Thum \\ Department of Biology, University of Fribourg, CH-1700 Fribourg, Switzerland
}

Insect mushroom bodies are required for diverse behavioral functions, including odor learning and memory. Using the numerically simple olfactory pathway of the Drosophila melanogaster larva, we provide evidence that the formation of appetitive olfactory associations relies on embryonic-born intrinsic mushroom body neurons (Kenyon cells). The participation of larval-born Kenyon cells, i.e., neurons that become gradually integrated in the developing mushroom body during larval life, in this task is unlikely. These data provide important insights into how a small set of identified Kenyon cells can store and integrate olfactory information in a developing brain. To investigate possible functional subdivisions of the larval mushroom body, we anatomically disentangle its input and output neurons at the single-cell level. Based on this approach, we define 10 subdomains of the larval mushroom body that may be implicated in mediating specific interactions between the olfactory pathway, modulatory neurons, and neuronal output.

\section{Introduction}

Like most animals, Drosophila is able to associate a particular odor with a rewarding or punishing stimulus (McGuire et al., 2005; Keene and Waddell, 2007). In adult insects, the mushroom bodies (MBs) have been implicated in the formation and recall of olfactory memory (Heisenberg, 2003; Menzel et al., 2006); this may even apply to Drosophila larvae (Gerber et al., 2004, 2009). Anatomically and functionally, the larval brain shares many of the organizational features known from the mammalian brain, yet comprises only $\sim 2000$ functional neurons (Iyengar et al., 2006; Vosshall and Stocker, 2007). Consequently, we used the Drosophila larva as a model for investigating olfactory learning at the cellular level.

Odor information is signaled in the larva by a set of 21 functionally distinct olfactory receptor neurons (Fishilevich et al., 2005) and $\sim 25$ unique second-order projection neurons (PNs) to higher olfactory centers, i.e., the lateral horn and the MB calyx (Ramaekers et al., 2005; Masuda-Nakagawa et al., 2009). In the calyx, PNs synapse onto Kenyon cells (KCs), which are the most prominent intrinsic neurons of the MBs (MBINs) despite another type of MBINs that are non-KCs but also exclusively innervate the MBs. Interestingly, how other sensory modalities are signaled onto the MBs and how output neurons collect the information from the MBs is hardly understood. Recent findings suggest that dopaminergic and octopaminergic neurons signal aversive and/or appetitive reinforcement onto the

\footnotetext{
Received March 12, 2010; revised May 12, 2010; accepted June 5, 2010.

This work was supported by the Swiss National Funds (to R.F.S., Grant 3100A0-105517). We thank M. Heisenberg, B. Gerber, J. Rister, K. Ito, Y. Aso, L. Masuda-Nakagawa, and H. Tanimoto for kindly providing fly strains and for their help on the manuscript. We are grateful to A. Jenett for providing the "cellcounter" plugin for ImageJ. All NP lines were obtained from Drosophila Genetic Resource Center at Kyoto Institute of Technology.

${ }^{*} D$.P. and M.S. contributed equally to this work.

Correspondence should be addressed to Andreas S. Thum, Department of Biology, University of Fribourg, Chemin du Musée 10, CH-1700 Fribourg, Switzerland. E-mail: andreas.thum@unifr.ch.

DOI:10.1523/JNEUROSCI.1281-10.2010

Copyright $\odot 2010$ the authors $\quad$ 0270-6474/10/3010655-12\$15.00/0
}

MBs (Schwaerzel et al., 2003; Schroll et al., 2006; Claridge-Chang et al., 2009; Honjo and Furukubo-Tokunaga, 2009; Mao and Davis, 2009; Selcho et al., 2009). Anatomically Tanaka et al. (2008) identified at least 24 different types of MB extrinsic neurons (MBENs) in adult flies.

In $\mathrm{MB}$ development, constant proliferation of four $\mathrm{MB}$ neuroblasts (Nbs) gives rise to $\sim 250-300 \mathrm{KCs}$ of embryonic origin and to a further $2000 \mathrm{KCs}$ of larval origin (Technau and Heisenberg, 1982; Ito and Hotta, 1992), forming together the three main compartments of the MBs: calyx, pedunculus, and lobes (Armstrong et al., 1998; Lee et al., 1999; Kurusu et al., 2002; Strausfeld et al., 2003). Newly born KCs send their axons into the core region of the pedunculus and push earlier born fibers to the surface, creating a characteristic layering of the pedunculus (Kurusu et al., 2002).

Interestingly, the four $\mathrm{MB} \mathrm{Nbs}$, and an additional lateral $\mathrm{Nb}$, are the only Nbs that continue to proliferate during larval life. The MB Nbs are also the last ones to divide during larval-adult transition (Technau and Heisenberg, 1982; Truman and Bate, 1988; Ito and Hotta, 1992). Thus, selective neurogenesis in the MBs is reminiscent of adult neurogenesis in the mammalian hippocampus (Cayre et al., 2007), a brain region implicated in memory formation.

Here we dissect the neuronal organization of the larval MBs with respect to intrinsic and extrinsic neurons, and we analyze the role of MB Kenyon cells in appetitive olfactory learning. We show that larval MBs are organized as distinct subdomains that are selectively innervated by different types of MBENs. Furthermore we provide evidence that the formation of appetitive olfactory associations in larvae relies on a small subset of embryonic-born $\mathrm{KCs}$. Hence, MB proliferation during larval life is not required for this task.

\section{Materials and Methods}

Fly strains. Flies were cultured according to standard methods. See the Supplemental Data (available at www.jneurosci.org as supplemental material) 

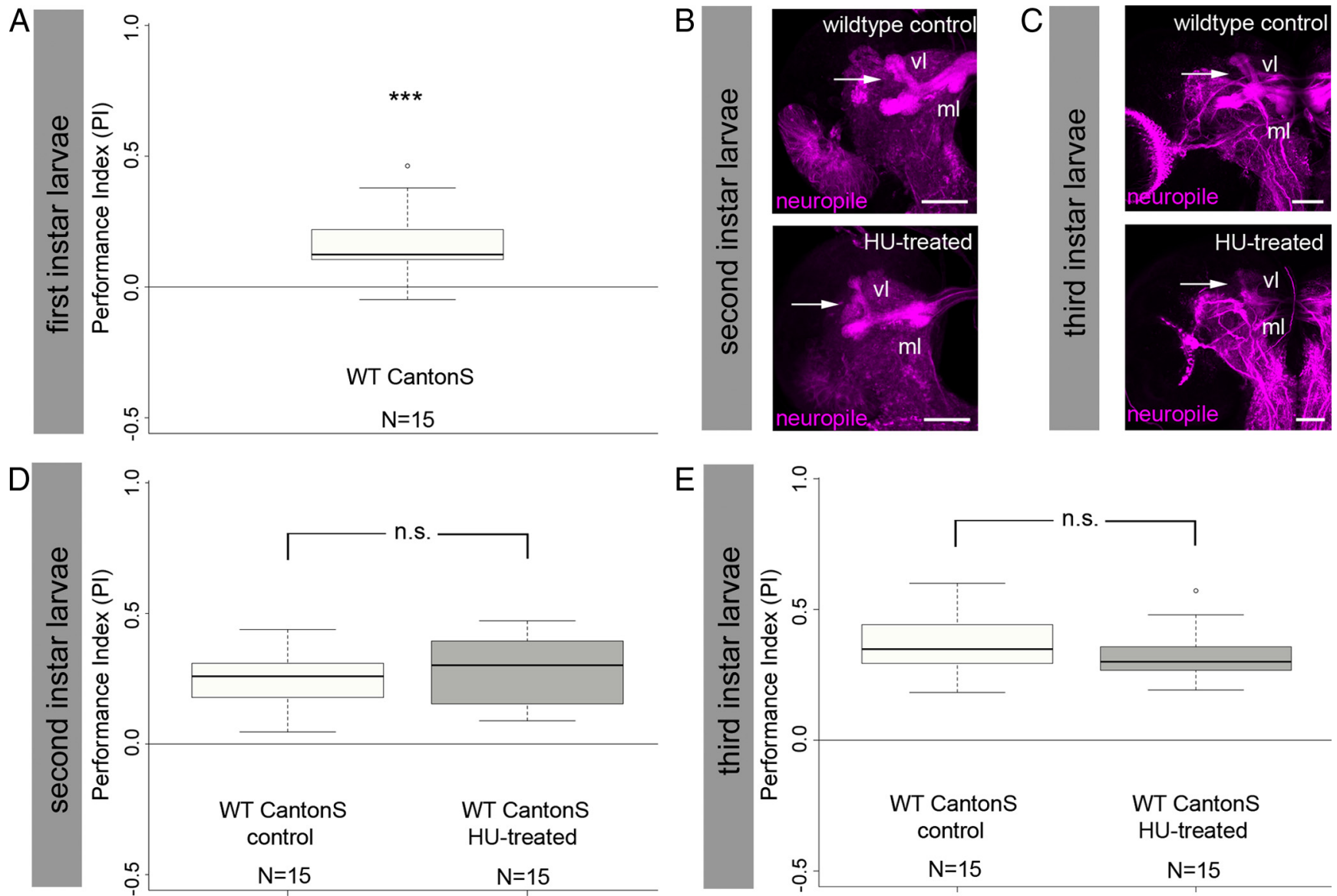

Figure 1. Mushroom bodies comprising exclusively embryonic-born Kenyon cells allow for larval appetitive olfactory learning. Even first instar wild-type larvae are able to form appetitive olfactory associations $(\boldsymbol{A} ; \boldsymbol{p}<0.001)$. HU treatment of first instar larvae removes larval-born $\mathrm{KC}$ resulting in a reduction of $\mathrm{MB}$ size and $\mathrm{KC}$ numbers compared to nontreated controls $(\boldsymbol{B}, \boldsymbol{C})$, especially when comparing vertical and medial lobes (arrows in $\boldsymbol{B}$ and $\boldsymbol{C}$; $v$ l and $\mathrm{ml}$ ). Performance of second and third instar wild-type larvae treated before with $\mathrm{HU}$ was not significantly different from controls $(\boldsymbol{D}, \boldsymbol{E} ; \boldsymbol{p}>0.05)$. Box plots represent an $N$ of 15 for each genotype. Medians are shown as crosslines, $50 \%$ of the values of a given genotype being located within the box; whiskers represent the entire set of data. For the comparison between experimental and control groups, Wilcoxon rank sum test was used. Behavioral assays were performed at room temperature. All anatomical pictures show a representative frontal view of projections of $z$-stacks of one hemisphere. Neuropil is stained by ChAT4B1 mouse antibody. Scale bars, $25 \mu \mathrm{m}$.

or Selcho et al. (2009) for fly stock source. For the behavioral experiments, UAS-shi ${ }^{\text {tsl }}$ was crossed to the MB-specific GAL4-driver lines. Heterozygous controls were obtained by crossing GAL4-driver and UASeffector to $w^{1118}$. For visualizing neurons, we used the UAS- $m C D 8:: G F P$ reporter. The driver lines $201 \mathrm{y}$ and NP1131 were crossed with MBGAL80; UAS-shi ${ }^{\text {tsl }}$ females (Krashes et al., 2007) and MBGAL80; UAS- $m C D 8:: G F P$. For cell counts, we used a triple insertion of UAS- $m C D 8:: G F P$ (Aso et al., 2009). Presynaptic and postsynaptic regions were labeled using UAS-nsyb::GFP and UAS-Dscam[17.1]::GFP, respectively (Ito et al., 1998; Wang et al., 2004). Expression patterns of the six MB-specific GAL4 driver lines were compared by crossing them with MB247-DsRed; UAS- $m C D 8:: G F P$ virgins (Riemensperger et al., 2005). For creating single-cell flp-out clones, $y w$ hsp70-flp; $S p / C y O$; UAS $>C D 2 y^{+}>m C D 8:: G F P / T M 6 b$ virgins (Wong et al., 2002) were crossed to males of a given GAL4 driver as published before (Selcho et al., 2009).

Screening of GAL4 lines for larval mushroom body expression. We screened 30 GAL4 drivers for expression in larval MB KCs (O'Dell et al., 1995; Yang et al., 1995; Connolly et al., 1996; Koushika et al., 1996; Amrein and Axel, 1997; Tettamanti et al., 1997; Kraft et al., 1998; Moreau-Fauvarque et al., 1998; McBride et al., 1999; Hayashi et al., 2002; Manoli et al., 2005; Keleman et al., 2007; Krashes et al., 2007; Tanaka et al., 2008). In addition, we screened another 64 GAL4 drivers (Tanaka et al., 2008) for expression in non-KC MBINs or in MBENs. A complete list of GAL4 driver lines and procedural details are given in the Supplemental Data (available at www.jneurosci.org as supplemental material). In gen- eral the driver lines were chosen based on their specific expression patterns during adult stage.

Behavioral experiments. Appetitive olfactory learning and naive preferences to the odors and tastants applied was tested using a standardized assay described before (Scherer et al., 2003; Hendel et al., 2005; Michels et al., 2005; Gerber and Hendel, 2006; Gerber and Stocker, 2007; Gerber et al., 2009; Selcho et al., 2009).

Statistical methods. For the comparison between genotypes, Wilcoxon rank sum test was used. To compare single genotypes against chance level, we used the Wilcoxon signed ranked test. All statistical analyses and visualizations were done with $\mathrm{R}$ version 2.8.0. Figure alignments were done with Adobe Photoshop. Data were presented as box plots, $50 \%$ of the values of a given genotype being located within the box, whiskers represent the entire set of data. Outsiders are indicated as open circles. The median performance index was indicated as a bold line within the box plot. Significance levels between genotypes shown in the figures refer to the $p$ values obtained in the statistical tests.

Hydroxyurea treatment. Hydroxyurea (HU) treatment was performed according to de Belle and Heisenberg, 1994. Control larvae were treated equally but exposed to yeast paste lacking HU.

Immunofluorescence. Similar to the procedural details described by Selcho et al. (2009), rabbit polyclonal serum against green fluorescent protein (anti-GFP; Invitrogen, 1:200) was used for analyzing GFP patterns and two different mouse antibodies for staining the neuropil (ChAT4B1; DSHB, 1:150) and the axonal tracts (1d4 anti-Fasciclin II; DSHB, 1:50) for first, second, and third instar larvae donated by P. M. 

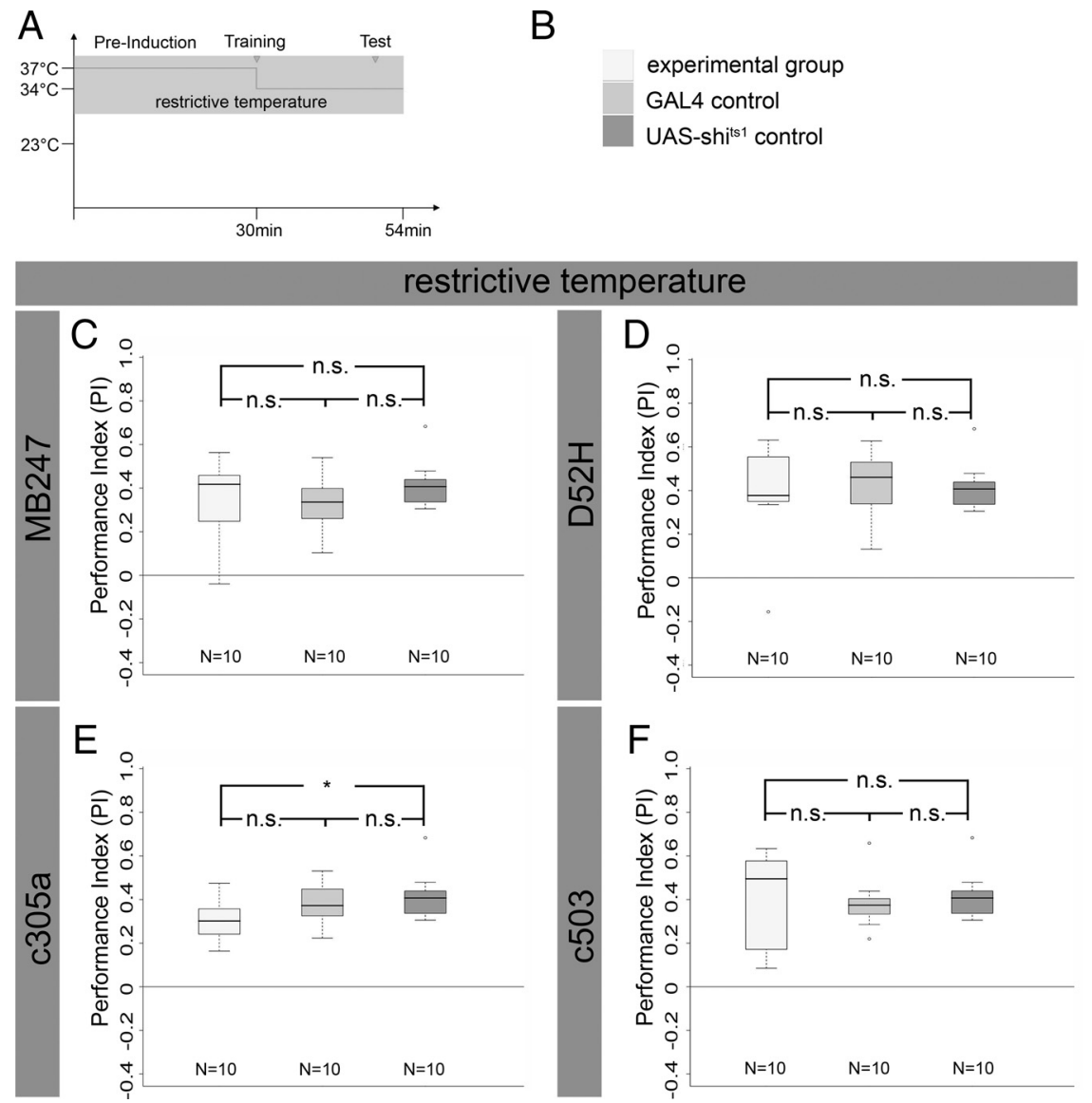

Figure 2. Appetitive olfactory learning is not impaired by blocking synaptic output of four of the six mushroom body GAL4 lines. Studying appetitive olfactory learning in $\mathrm{F} 1$ larvae of a cross between MB247, D52H, C305a, or $c 503$ and UAS-shit ${ }^{\text {t5 } 1}$ did not reveal any significant reduction in memory performance when conditionally blocking synaptic output during training and test $(A ; C-F$; $p>0.05$ ). The different patterns of the box plots in $\mathbf{C} \boldsymbol{F}$ are explained in $\boldsymbol{B}$. Box plots represent an $N$ of 10 for each genotype. The whole experiment (of $54 \mathrm{~min}$, including an initial heat shock) was performed at restrictive temperature as indicated by the shaded field. Medians are shown as crosslines, $50 \%$ of the values of a given genotype being located within the box; whiskers represent the entire set of data. For comparison between genotypes, Wilcoxon rank sum test was used. See also supplemental Table S1 (available at www.jneurosci.org as supplemental material) for detailed anatomical information.

Salvaterra and C. Goodman. Images were taken with a LeicaTCS SP5 confocal microscope with $\times 20$ or $\times 63$ glycerol objectives. The resulting image stacks were projected and analyzed with ImageJ software (NIH). Contrast and brightness adjustment as well as rotation and organization of images were performed in Photoshop (Adobe Systems).

Anatomical data processing. For cell counting, inverted grayscale stacks of the green channel were manually counted using a customized macro for Image (NIH) called "cellcounter." Based on the coordinate information, the centers of the nuclei of the labeled cells were marked in the present slice and in one or two previous or following slices by different colors, respectively. Typically, one nucleus spanning different confocal sections was automatically marked twice or three times in the close vicinity. By manually checking duplicated markers in neighboring slices, we subtracted these redundant counts. We counted at least 10 calyces for each of the six MB-specific GAL4 lines crossed to 3x UAS-mCD8::GFP. Final numbers were further processed by Microsoft Excel.

For 3D reconstruction of MBs, labels were manually created around individual subregions of a third instar MB in a H24; UAS- $m C D 8:: G F P$ stack using the ImageJ plugin "segmentation editor." Then, texturebased volume rendering was applied using the ImageJ plugin " $3 \mathrm{D}$ Viewer." Reconstructions of MBINs and MBENs were performed by texture-based volume rendering of single stacks of the green channel using the ImageJ plugin "3D Viewer." MB reconstructions in these cases were first preprocessed by manually creating a label around MB lobes, pedunculus, and calyx. Subsequently, texture-based volume rendering was applied on these labels using ImageJ plugin "3D Viewer," which was also used to combine neuron and $\mathrm{MB}$ reconstructions.

Supplemental Data. Supplemental Data, including figures and tables, and Supplemental Experimental Procedures are available at www. jneurosci.org as supplemental material.

\section{Results}

\section{Larval appetitive olfactory learning} relies on a subset of embryonic-born Kenyon cells

In adult flies, MBINs, arborizing exclusively within MBs, consist of several types of $\mathrm{KCs}$ and three types of non-KCs (Tanaka et al., 2008). For third instar larvae, only three different types of KCs were identified as MBINs: embryonic-born $\gamma$ type, larval-born $\gamma$ type, and larval-born $\alpha^{\prime} / \beta^{\prime}$ type KCs (Lee et al., 1999; MasudaNakagawa et al., 2005; Ramaekers et al., 2005). In adults, the role of subtypes of MBINs in olfactory memory formation was addressed in several studies. Briefly, $\gamma$ type KCs have been suggested to support short-term memory, whereas $\alpha / \beta$ type KCs were considered as playing an important role in long-term memory. For $\alpha^{\prime} / \beta^{\prime}$ type $\mathrm{KCs}$, it has been claimed that neural transmission of these neurons is required for acquisition and stabilization of odor memory (Heisenberg et al., 1985; McGuire et al., 2001; Pascual and Préat, 2001; Schwaerzel et al., 2003; Yu et al., 2005, 2006; Krashes et al., 2007).

To functionally dissect the larval KC types in a comparable way, we applied a recently established larval classical conditioning paradigm that uses two odorants as conditioned stimuli and fructose as an unconditioned stimulus (Hendel et al., 2005; Michels et al., 2005; Gerber et al., 2009). For analyzing the role of embryonic-born KCs in larval odor-sugar learning, we first studied first instar larvae, whose MBs comprise exclusively embryonic-born KCs. First instar wild-type larvae showed significant appetitive olfactory learning $\left(p=1.8 \times 10^{-4}\right)($ Fig. $1 \mathrm{~A})$. Alternatively we tested second and third instar larvae whose MBs were chemically deprived of larvalborn KCs. This was achieved by feeding the mitosis-inhibiting agent $\mathrm{HU}$ to newly hatched first instar larvae, thereby blocking selectively the Nbs proliferating during this period, i.e., the four $\mathrm{MB} \mathrm{Nbs}$ and the additional lateral $\mathrm{Nb}$ (Technau and Heisenberg, 1982; de Belle and Heisenberg, 1994; Stocker et al., 1997; Armstrong et al., 1998). Deletion of all KC lineages except the embryonicborn KCs was confirmed in whole mounts of the brain stained by anti-Fasciclin II (FasII) and anti-Choline acetyltransferase $(C h A T)$ antibodies as neuropil markers (Fig. 1D,E). Second and third instar wild-type larvae treated with $\mathrm{HU}$ as first instars did not show any significant reduction in learning compared to nontreated control larvae ( $p=0.44 \mathrm{~s}$ instar compared with HU control; $p=0.29$ third instar compared with HU control) (Fig. $1 B, C)$. These data demonstrate that normal first instar larvae, as well as second and third instar larvae whose MBs are deprived of 

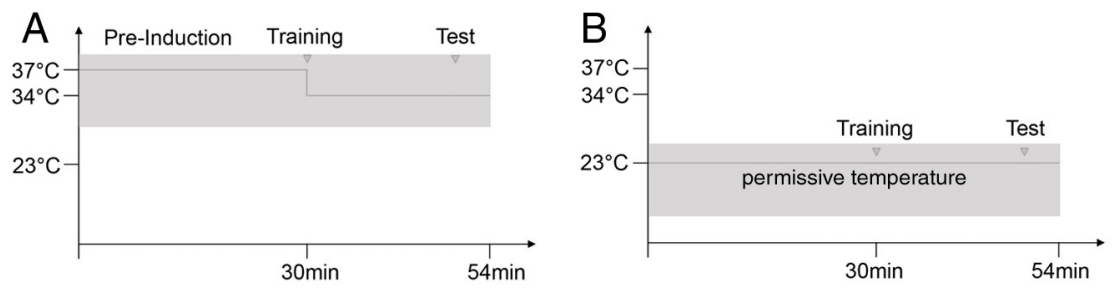

C

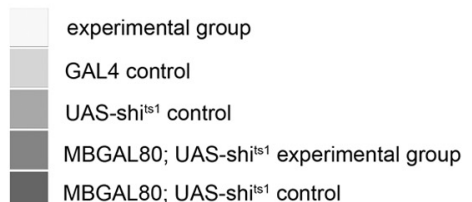

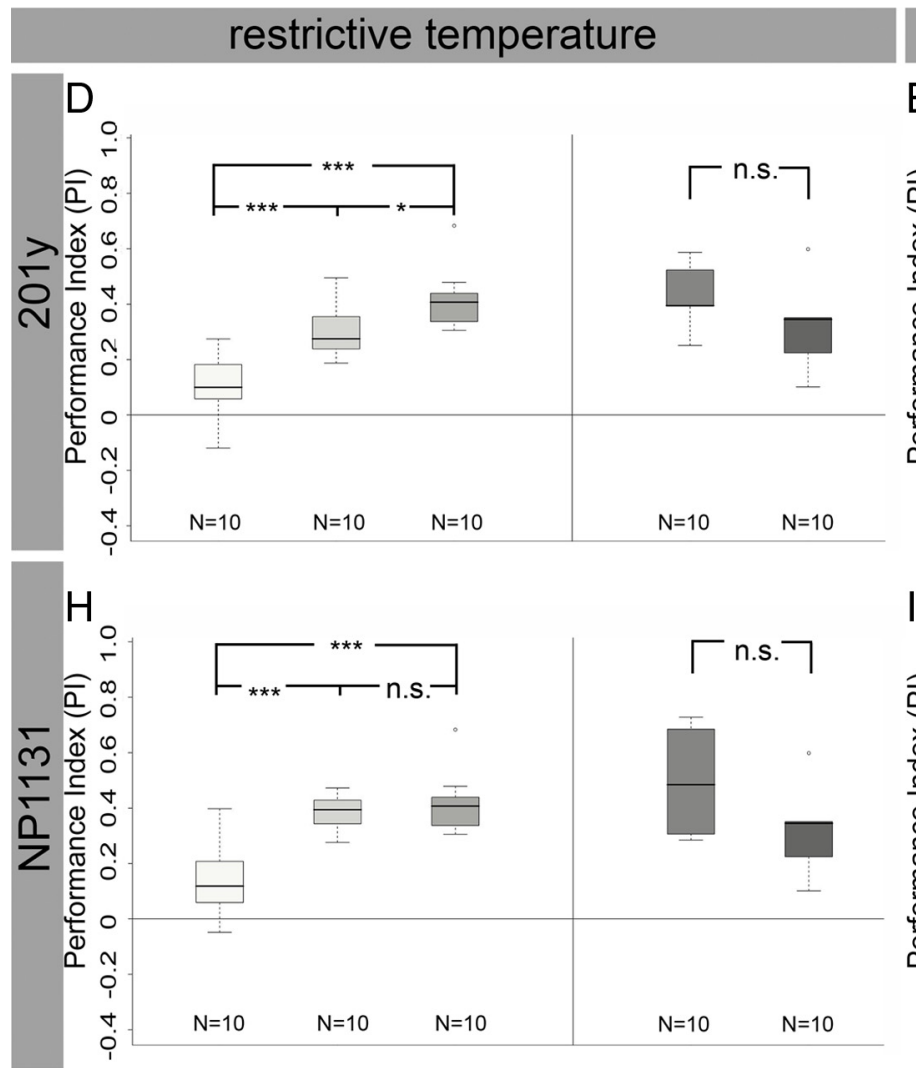

permissive temperature
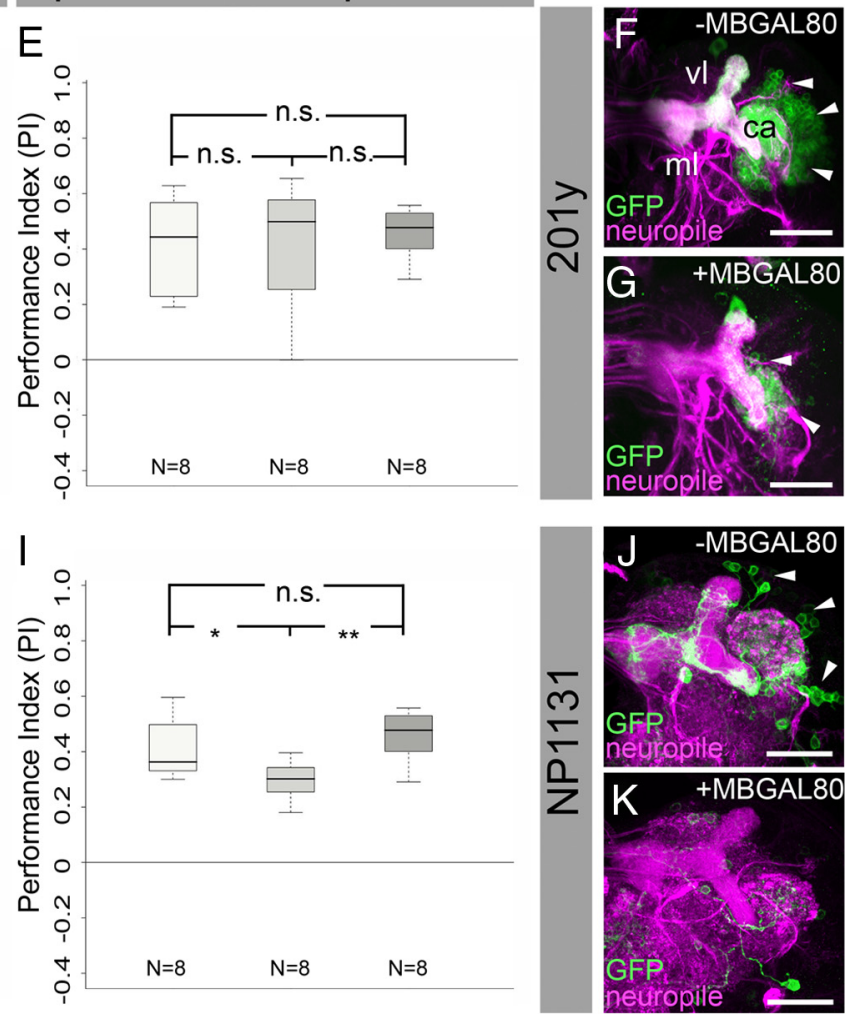

Figure 3. Appetitive olfactory learning is impaired by blocking synaptic output of embryonic-born Kenyon cells. Studying appetitive olfactory learning in 201y/UAS-shit ${ }^{\text {ts } 1}$ and NP1131/UAS-shits larvae at restrictive temperature $(\boldsymbol{A})$ revealed a significantly impaired performance (left panel in $\boldsymbol{D}, \boldsymbol{H} ; \boldsymbol{p}<0.05$ ). Such memory impairment was absent when larvae were trained and tested at permissive temperature $(\boldsymbol{B}, \boldsymbol{E}, \boldsymbol{I} ; \boldsymbol{p}>0.05)$ or when introducing MBGAL80 at restrictive temperature (right panel in $\boldsymbol{D}, \boldsymbol{H} ; \boldsymbol{p}>0.05)$ that inhibits GAL4 activity in KCs partially for $201 \mathrm{y}$ (compare $\boldsymbol{F}$ and $\mathbf{G}$ ) or completely for NP1131 (compare $\boldsymbol{J}$ and $\boldsymbol{K}$ ). The different patterns of the box plots in $\mathbf{D}-\boldsymbol{I}$ are explained in $\boldsymbol{C}$. Box plots represent an $N$ of 8 or 10 for each genotype. The whole experiment (of 54 min, including an initial heat shock) was performed at restrictive temperature as indicated by the shaded field. Medians are shown as crosslines, $50 \%$ of the values of a given genotype being located within the box; whiskers represent the entire set of data. For comparison between genotypes, Wilcoxon rank sum test was used. $\boldsymbol{F}-\boldsymbol{K}$ each shows a frontal view onto a representative projection of $z$-stacks of a brain hemisphere of the given genotype. vl, Vertical lobe; $\mathrm{ml}$, medial lobe; ca, calyx; mushroom body Kenyon cell bodies are highlighted by arrowheads. Scale bars, $25 \mu \mathrm{m}$. See also supplemental Tables S1 and S2 (available at www.jneurosci.org as supplemental material) for anatomical details and sensory acuity tests.

larval-born KCs, are able to form odor-sugar associations $(p=$ $6.1 \times 10^{-5}$ for HU-treated second instar larvae; $p=6.1 \times 10^{-5}$ for HU-treated third instar larvae).

In a second experiment, we asked which sets of embryonic- or larval-born KCs are necessary for larval odor-sugar learning. We applied the GAL4/UAS system that allows one to reproducibly express a given effector gene in a genetically defined set of cells, for cellular visualization (e.g., by expressing the green fluorescent protein GFP) or for conditional block of neurotransmission (e.g., via the temperature-sensitive dominant-negative shibire ${ }^{t s 1}$ gene) (Brand and Perrimon, 1993; Kitamoto, 2001; Duffy, 2002). We crossed six GAL4 driver lines that had been identified from 94 lines in our anatomical screen (supplemental Table S1, available at www.jneurosci.org as supplemental material) and preferentially express GAL4 either in embryonic-born $\gamma$ type KCs (D52H and NP1131), in embryonic- and larval-born $\gamma$ type KCs (201y and MB247) or in larval-born $\alpha^{\prime} / \beta^{\prime}$ type KCs (c305a and c503) (see below) (see Fig. 4) with the UAS-shi ${ }^{\text {tsl }}$ responder transgene to block synaptic output of these neurons (Kitamoto, 2001). Because $s h i^{t s l}$ can be conditionally activated, we were able to interfere with neurotransmission specifically during the time of the learning experiment, by that excluding developmental phenotypes.

At restrictive temperature, none of the four experimental larvae, MB247/UAS-shit ${ }^{t s 1}$, D52H/UAS-shi ${ }^{t s 1}, \mathrm{c} 305 \mathrm{a} / \mathrm{UAS}-s h i^{t^{t s} l}$, and c503/UAS-shitsl showed significantly reduced performance scores compared to the GAL4/+ and UAS/+ controls (Fig. 2). Yet, c305a/UAS-shitsl, while not being reduced compared to GAL4/ + (Fig. 2E) (for all, $p>0.05$ ) was reduced compared to UAS-shis $i^{t s 1}+(p=0.043)$. In contrast, 201y/UAS-shi $i^{t s l}$ and NP1131/UAS-shi ${ }^{\text {tsl }}$ larvae performed significantly less well at restrictive temperature in the appetitive olfactory learning assay than their respective GAL4/+ and UAS/+ controls (201y/UAS$\operatorname{shi}^{t s 1}$ vs $201 \mathrm{y} /+p=0.0003$; vs UAS-shits $p=1.8 \times 10^{-5}$; 

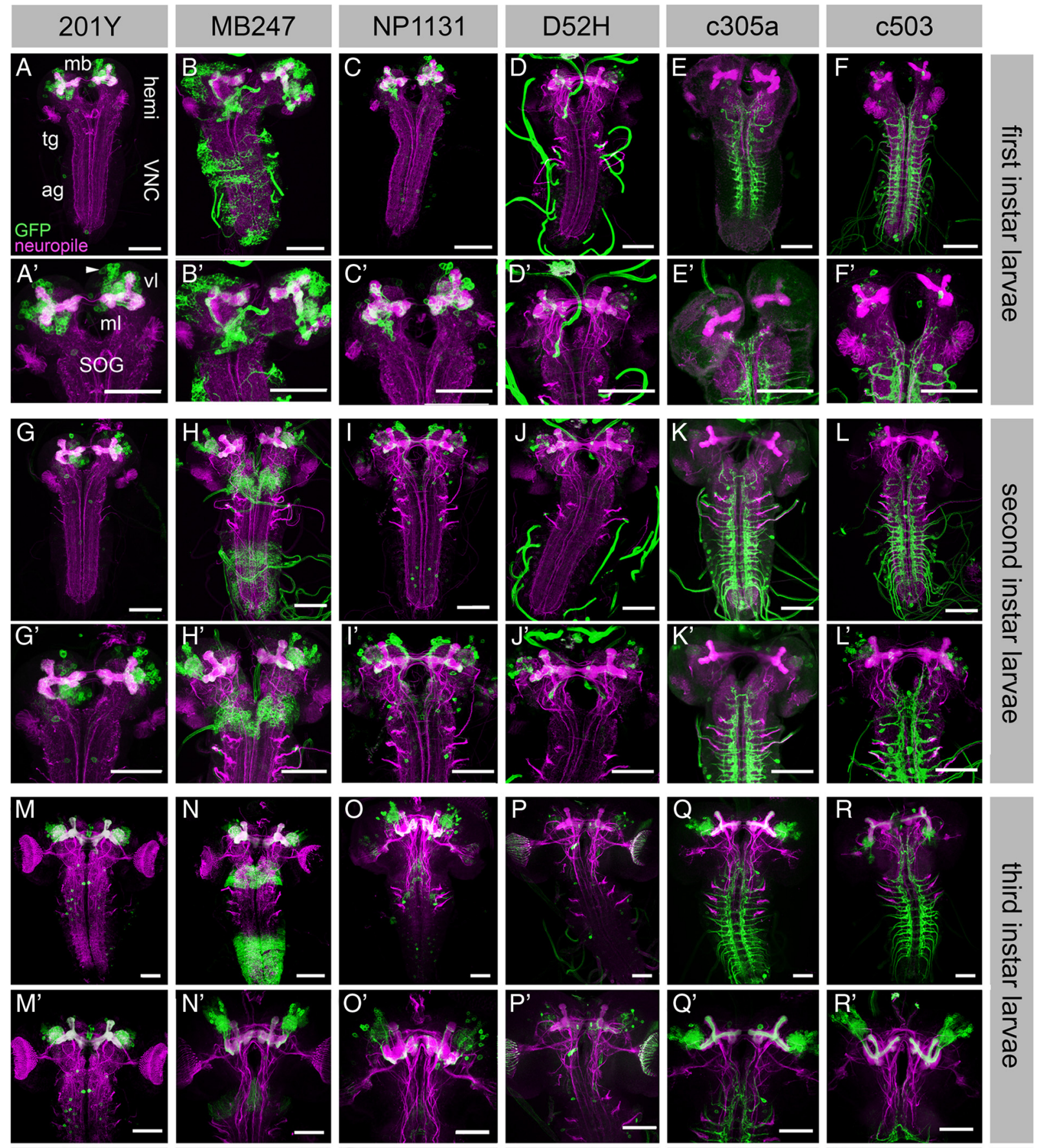

高.
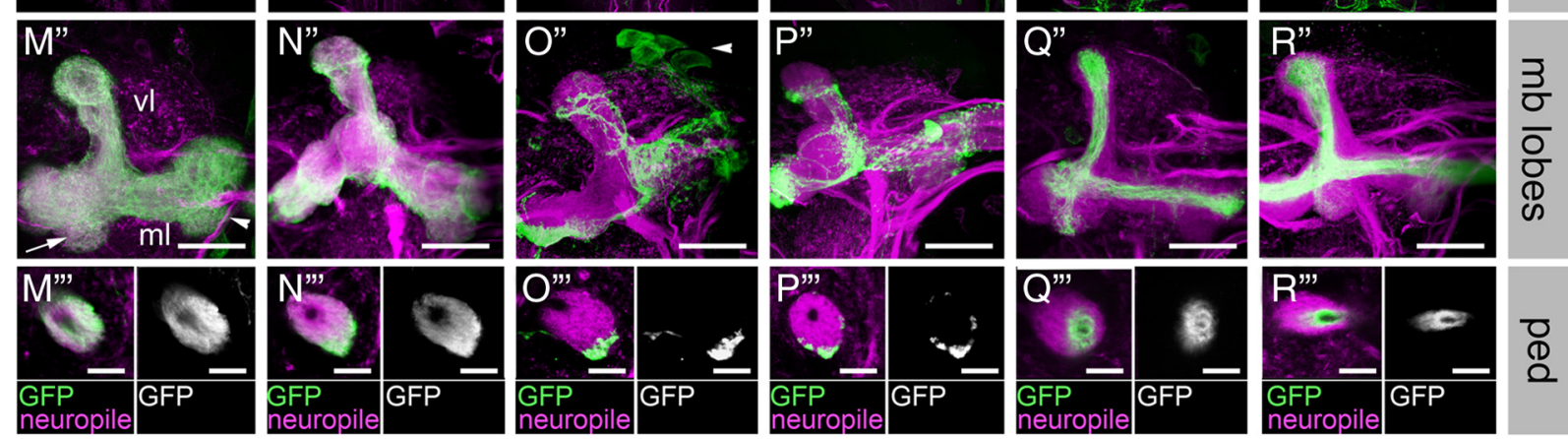

\section{broad expression}

surface expression

core expression

Figure 4. Expression patterns of six mushroom body GAL4 lines through larval development. 201y, MB247, NP1131, D52H, c305a, and c503 were crossed with UAS-m CD8:GFP and double stained by anti-GFP (green) and anti-Fasciclin I//anti-Choline acetyltransferase (neuropil markers; magenta). The different rows are explained on the right side of the figure. On the (Figure legend continues.) 
Table 1. Expression pattern analysis of six mushroom body-specific GAL4 driver lines

\begin{tabular}{|c|c|c|c|c|c|c|}
\hline GAL4 line & $201 y$ & $\mathrm{mb} 247$ & NP1131 & $\mathrm{D} 52 \mathrm{H}$ & C 305 & C503 \\
\hline \multicolumn{7}{|l|}{ Mushroom body expression } \\
\hline Number of Kenyon cells at the first instar & $72 \pm 8$ & $54 \pm 4$ & $25 \pm 2$ & $7 \pm 1$ & $23 \pm 2$ & $12 \pm 1$ \\
\hline Number of Kenyon cells at the second instar & $128 \pm 9$ & $160 \pm 6$ & $25 \pm 2$ & $7 \pm 1$ & $59 \pm 6$ & $42 \pm 1$ \\
\hline Number of Kenyon cells at the third instar & $315 \pm 14$ & $341 \pm 25$ & $27 \pm 2$ & $8 \pm 1$ & $189 \pm 13$ & $113 \pm 8$ \\
\hline UAS-nsyb::GFP expression in the lobes & Yes & Yes & Yes & Yes & Weak & No \\
\hline UAS-nsyb::GFP expression in the calyces & Yes & Yes & Yes & Yes & Weak & Yes \\
\hline UAS-Dscam17.1::GFP expression in lobes & No & No & No & No & No & No \\
\hline UAS-Dscam17.1::GFP expression in calyces & Yes & Yes & Yes & Yes & Weak & Weak \\
\hline \multicolumn{7}{|c|}{ Expression outside of the mushroom body at the third instar } \\
\hline Ring gland & + & - & - & + & - & - \\
\hline DILP neurons & - & - & ++ & - & - & - \\
\hline Unidentified neurons in the brain & + & - & + & + & + & + \\
\hline Ventral nerve cord & + & - & + & - & ++ & ++ \\
\hline Glia & - & ++ & - & - & - & - \\
\hline
\end{tabular}

,- No expression; + , low expression; ++ , high expression. Values are given as mean \pm SEM.

NP1131/UAS-shit ${ }^{t s l}$ vs NP1131/ $+p=0.0002$; vs UAS-shi $i^{t s 1} p=$ 0.0001 ) (Fig. 3D, $H$ ). However, the performance of 201y/UAS$\operatorname{shi}^{\text {tsl }}(p=0.027)$ and NP1131/UAS-shit ${ }^{\text {tsl }}(p=0.005)$ larvae was still above chance level (Fig. $3 D, H$ ). For none of the two crosses, a significant reduction in performance was detected at permissive temperature (Fig. $3 B, E, I$ ) (for all, $p>0.05$, except for NP1131/ UAS-shits ${ }^{t s}$ vs NP1131/+, which is significantly increased, $p=$ 0.028 ) and their general sensory acuity was also not different from their appropriate controls (supplemental Table S2, available at www.jneurosci.org as supplemental material) $(p>0.05)$.

The only region of overlapping expression between the two lines 201y and NP1131 affected by the blocking experiment are embryonic-born $\gamma$ type KCs (see also supplemental Fig. S2, available at www.jneurosci.org as supplemental material). To determine whether the memory loss in the previous experiments was indeed due to synaptic block of MB neurons labeled by 201y and NP1131, we incorporated the MBGAL80 transgene, which represses GAL4 activity in MBs (Lee et al., 1999). When combining the MBGAL80 insertion with these drivers crossed to UAS- $m C D 8:: G F P$, only a small set of KCs was labeled with the $201 \mathrm{y}$ driver (Fig. $3 F, G$ ) and none at all with NP1131 (Fig. 3J,K). Therefore, the presence of MBGAL80 specifically abolished GAL4 activity in MBs but left expression elsewhere largely intact. After conditioning and testing at restrictive temperature, neither 201y/MBGAL80/UAS-shits ${ }^{\text {ts }}$ larvae nor NP1131/MBGAL80/ UAS-shis ${ }^{\text {ts }}$ larvae were reduced in appetitive olfactory learning compared to their appropriate controls (Fig. 3D,H) (for 201y/ MBGAL80/UAS-shi $i^{t s l}$ compared to MBGAL80/UAS-shit ${ }^{t s l} /+, p=$ 0.911; for NP1131/MBGAL80/UAS-shit ${ }^{\text {tsl }}$ compared to MBGAL80/ UAS-shits $/+, p=1.000$ ). These data suggest that synaptic output of specific subsets of embryonic-born KCs is necessary for establishing larval appetitive olfactory learning.

\footnotetext{
(Figure legend continued.) bottom, a classification of the drivers with respect to their expression in the laminar layers of the pedunculus is given. All pictures represent a representative frontal view of projections of $z$-stacks. $A$, hemi, Brain hemispheres; VNC, ventral nerve cord; $\mathrm{mb}$, mushroom body; $\mathrm{tg}$, thoracic ganglion; ag, abdominal ganglion. $\boldsymbol{A}^{\prime}$, vl, Vertical lobe of the $\mathrm{mb}$; $\mathrm{ml}$, medial lobe of the mushroom body; $\mathrm{SOG}$, suboesophageal ganglion. $\boldsymbol{M}^{\prime \prime}$, vl, Vertical lobe of the $\mathrm{mb}$; $\mathrm{ml}$, medial lobe of the $\mathrm{mb}$; lateral appendix (arrow); medial appendix (arrowhead); $\mathbf{0}^{\prime \prime}$, DILP neurons (arrowhead). Scale bars: $25 \mu \mathrm{m}$ in $\boldsymbol{A}-\boldsymbol{F}^{\prime}, 50 \mu \mathrm{m}$ in $\mathbf{G}-\boldsymbol{R}^{\prime}, 10 \mu \mathrm{m}$ in $\boldsymbol{M}^{\prime \prime}-\boldsymbol{R}^{\prime \prime \prime}$. See also supplemental Figures $\mathrm{S1}$ and $\mathrm{S2}$ (available at www.jneurosci.org as supplemental material).
}

\section{Expression patterns of the behaviorally analyzed driver lines} in the larval mushroom bodies

To comprehensively analyze the expression patterns of the six behaviorally tested driver lines in first, second, and third instar larvae, we crossed them with UAS- $m C D 8:: G F P$ and stained the neuropil with anti-FasII and anti-ChAT antibodies (Fig. 4, Table 1 ; supplemental Table S1, available at www.jneurosci.org as supplemental material). In addition, labeled KCs were counted at each larval instar in at least $10 \mathrm{MBs}$ per genotype (Table 1). Crossing the lines with UAS-nsyb::GFP and UAS-Dscam 17.1::GFP (Ito et al., 1998; Wang et al., 2004) allowed us to disentangle, respectively, the presynaptic and postsynaptic organization of neurons (Fig. 5, Table 1).

The 201y line expresses GAL4 in a broad set of embryonicand larval-born KCs (Fig. 4A, G,M, Table 1; supplemental Table $S 1$, available at www.jneurosci.org as supplemental material), but also labels a small number of other neurons in the brain, ring gland, and ventral nerve cord (VNC) (Fig. 4M, $M^{\prime}$ ). Expression in MB247 includes a large set of embryonic- and larval-born $\gamma$ neurons as well as glia cells in the VNC (Fig. $4 B, H, N$, Table 1; supplemental Table S1, available at www.jneurosci.org as supplemental material). As none of these two drivers labels the core of the pedunculus at the third instar, it is unlikely that they cover larval-born $\alpha^{\prime} / \beta^{\prime}$ neurons (Fig. $\left.4 M^{\prime \prime \prime}, N^{\prime \prime \prime}\right)$. NP1131 and D52H specifically stain a small set of $\sim 25$ and 7 embryonic-born $\gamma$ neurons, respectively, because both patterns cover exclusively the surface layer of the third instar pedunculus (Fig. $4 O^{\prime \prime \prime}, P^{\prime \prime \prime}$ ) and are visible already at the first instar (Fig. 4C,D, Table 1; supplemental Table S1, available at www.jneurosci.org as supplemental material). NP1131 labels variable types of neurons in the entire CNS, such as neurons in the visual system or DILP-type neurons (Fig. $4 O, O^{\prime \prime}$, Table 1) (Drosophila insulin-like protein) (Ikeya et al., 2002), whereas D52H additionally stains neurons projecting to the visual system, the ring gland as well as peripheral nerve glia (Fig. $4 J^{\prime}, P^{\prime}$, Table 1). Finally, c305a and c503 label larval-born $\alpha^{\prime} / \beta^{\prime}$ KCs in the third larval instar, as suggested from their trajectory through the core of the pedunculus (Fig. $4 E, K, Q$, Table 1; supplemental Table S1, available at www.jneurosci.org as supplemental material) and they stain elements in the thoracic and abdominal ganglia, mostly sensory terminals from the periphery.

When crossed with UAS-Dscam17.1::GFP (Wang et al., 2004), the four drivers 201y, MB247, NP1131, and D52H highlighted the calyces, but neither the pedunculus nor the lobes (Fig. 5A-D, lower rows). In contrast, when crossed with UAS- $n s y b:: G F P$ (Ito 

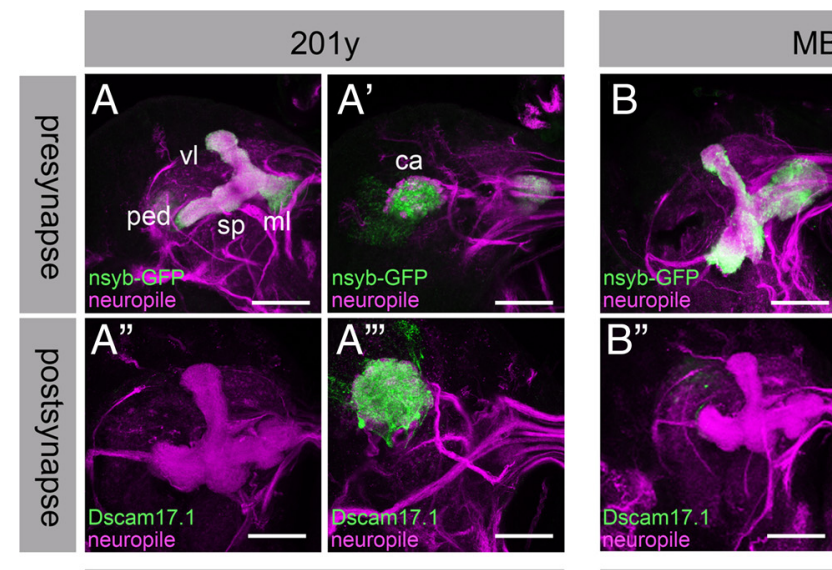

MB247
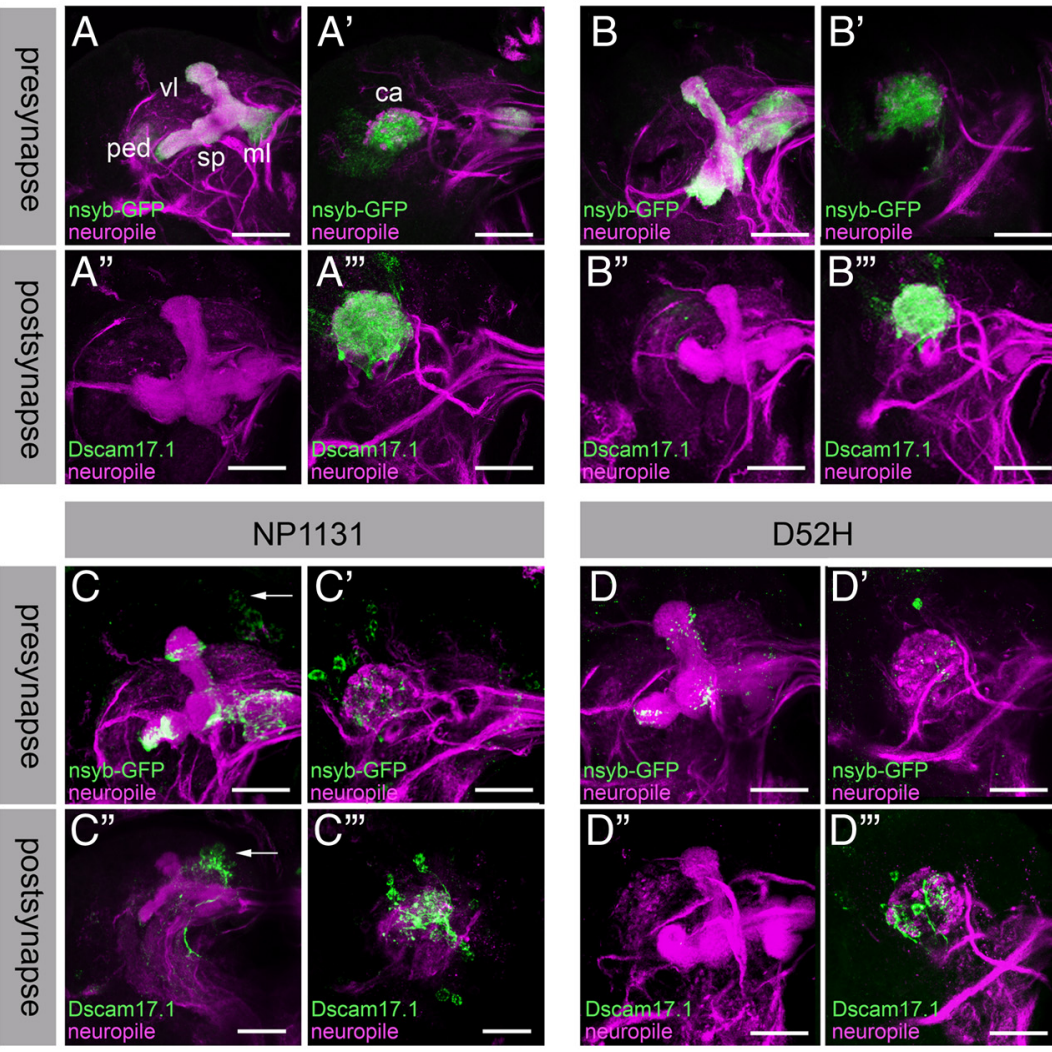

c305a

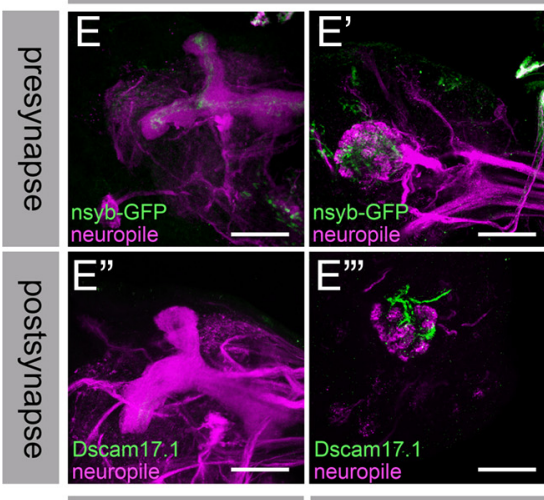

$\mathrm{mb}$ lobe

$\mathrm{mb}$ calyx
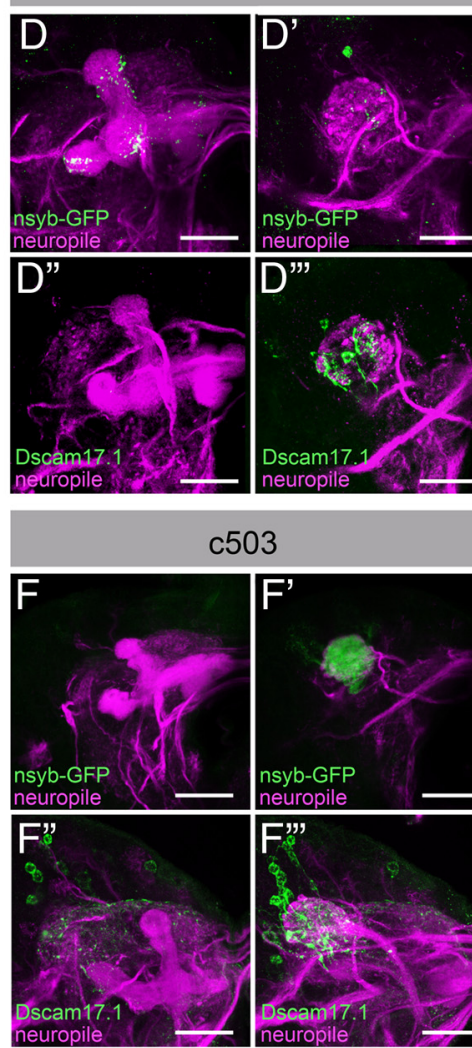

$\mathrm{mb}$ lobe

Figure 5. Presynaptic and postsynaptic expression in the six mushroom body GAL4 lines. To visualize presynaptic and postsynaptic sites, each line was crossed to UAS-nsyb:GFP and UAS-Dscam 17.1:GFP, respectively. Third instar larval brains were double stained by anti-GFP (green) and anti-Fasciclin I//anti-Choline acetyltransferase (magenta). 201y, MB247, NP1131, and D52H show distinct presynaptic staining in the lobes and calyx ( $\boldsymbol{A}-\boldsymbol{D}$, upper rows), while c305a shows only weak presynaptic staining in these two regions $\left(\boldsymbol{E}, \boldsymbol{E}^{\prime}\right)$. In $\mathrm{c} 503$ presynaptic staining is only visible in the calyx $\left(\boldsymbol{F}, \boldsymbol{F}^{\prime}\right)$. Postsynaptic staining is detected exclusively in the calyx, strongly in $201 y$ and mb247 ( $\boldsymbol{A}, \boldsymbol{B}$, lower rows) and less intensely for the other four GAL4 driver lines ( $\boldsymbol{C}-\boldsymbol{F}$, lower rows). All pictures represent projections of $z$-stacks. Ped, Pedunculus; $\mathrm{vl}$, vertical lobe of the $\mathrm{mb} ; \mathrm{ml}$, medial lobe of the $\mathrm{mb}$; $\mathrm{sp}$, spur; ca, calyx. Arrowheads in C and $C^{\prime \prime}$ highlight DILP neurons. Scale bars, $25 \mu \mathrm{m}$.

et al., 1998), all four drivers labeled the lobes and, at lower intensity, the calyces (Fig. $5 A-D$, upper rows). These results suggest that these four lines express GAL4 in different sets of embryonicand larval-born $\gamma$ neurons that have presynaptic and postsynaptic sites in the calyces, as recently reported for the adult MBs (Leiss et al., 2009), while being exclusively presynaptic in the lobes. c305a crossed to UAS-nsyb::GFP very weakly labeled both calyx and lobes (Fig. $5 E, E^{\prime}$ ). Driving UAS-Dscam17.1::GFP via
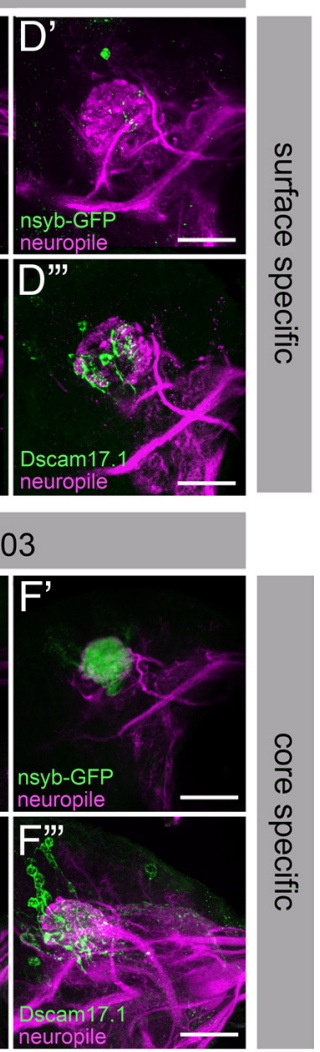

$\mathrm{mb}$ calyx c305a and c503 revealed weak expression in the calyx (Fig. $5 E, F$, lower rows). Hence, these two drivers likely express GAL4 mainly in larval-born $\alpha^{\prime} / \beta^{\prime}$ neurons, which are not functional in third instar larvae, in agreement with the findings by Lee et al. (1999).

Together the behavioral and anatomical data suggest that embryonic-born KCs included in the expression patterns of $201 \mathrm{y}$ and NP1131, but not in the expression patterns of MB247 and D52H, harbor a memory trace for larval odor-sugar learning (see also supplemental Fig. S1, available at www.jneurosci.org as supplemental material).

GAL4 driver analysis of extrinsic and intrinsic neurons defines subdomains of the larval mushroom body

In adult Drosophila, KCs, additional MBINs and MBENs contribute to the MBs (Tanaka et al., 2008). The morphology of these cell types provides important insights into possible anatomical subdivisions of this center and provides a first idea how unconditioned stimuli may be delivered to and how memory may be read out from the MBs. For this purpose, we screened third instar expression patterns of a set of 64 GAL4 lines that were reported to express GAL4 in adult MBENs and MBINs (H. Tanimoto, personal communication; Tanaka et al., 2008). We were indeed able to identify both MBENs and non-KC MBINs in the larva, in particular when applying the flp-out system to trace single neurons in a complex GAL4 expression pattern. To facilitate comparison between larval and adult stages, we applied the adult nomenclature for MBENs and MBINs (Tanaka et al., 2008). However, because we did not trace these neurons during metamorphosis, we are unable to draw any conclusions about homologies between larval and adult neurons with similar morphologies.

Remarkably, for a given type of neuron there was very little variability in arborization. We identified seven types of MBENs (Fig. 6A-G), which we categorized according to the MB subdomains they innervated (for subdomain definition, see Fig. 7). Three types (Fig. $6 A, B, D$ ) of the here shown MBENs were published before (Selcho et al., 2009) and are completed by another set of four MBENs (Fig. 6C,E-G). The putative dopaminergic neurons DL1-1 and DL1-2 (Selcho et al., 2009) labeled by the TH-GAL4 line innervated, respectively, the tip region (V3) and the shaft region (V2) of the ipsilateral and contralateral vertical lobe (Fig. $6 A, B)$. A single neuron identified by NP3128 innervated ipsilaterally the base (V1) of the vertical lobe (Fig. $6 C$ ). The DL1-5 neuron (Selcho et al., 2009) visualized by TH-GAL4 innervated 


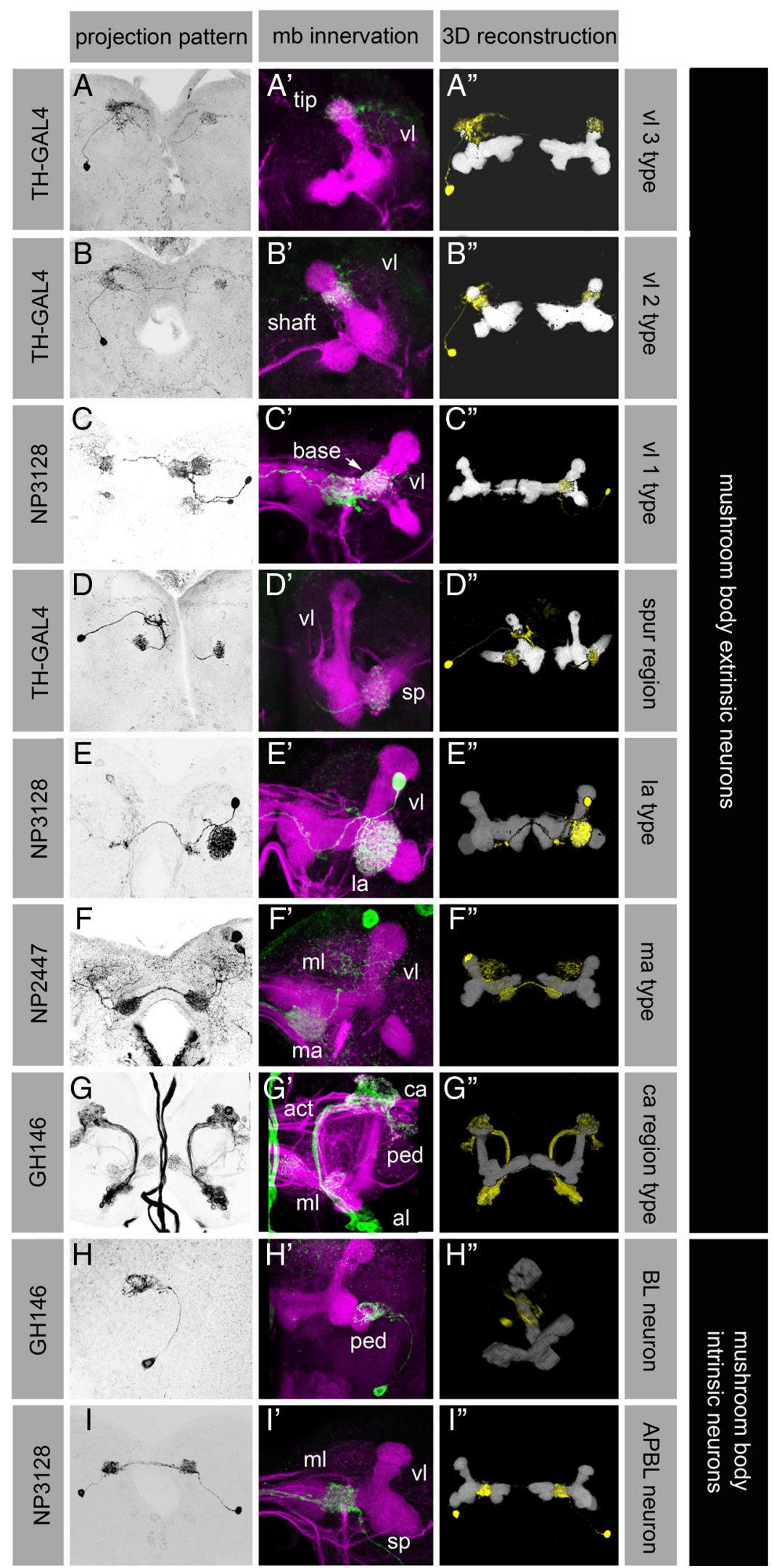

Figure 6. Screening for extrinsic and non-Kenyon cell intrinsic neurons of the mushroom body. For each of the seven analyzed types of MBENs and two types of non-KCMBINs, the expression pattern (anti-GFP channel; $A-I$ ), the innervation of the MB neuropil (anti-GFP and anti-Fasciclin II/anti-Choline acetyltransferase channels [magenta: neuropil marker]; $\boldsymbol{A}^{\prime}-\boldsymbol{I}^{\prime}$ ), its overlap with a 3D reconstruction of the MBs $\left(A^{\prime \prime}-I^{\prime \prime}\right)$ and its categorization according to the innervated MB subdomain (right) is shown. MBENs innervate the tip (V3 subdomain; $\boldsymbol{A}$ ), shaft (V2; $\boldsymbol{B})$, or base of the vertical lobe (V1; $\boldsymbol{C})$, the spur (D), the lateral appendix (LA; $\boldsymbol{E})$, the medial appendix (MA; $\boldsymbol{F})$, or the calyx $(\boldsymbol{G})$. MBENs specifically innervate the pedunculus $(\boldsymbol{H})$ or the medial lobe (M1 subdomain; $\boldsymbol{I})$. exclusively the spur of ipsilateral and contralateral MBs (Fig. 6D). Another neuron of NP3128 innervated the lateral appendix (LA) ipsilaterally and a small region basal to the ipsilateral and contralateral medial lobe (Fig. 6E). A single neuron of NP2447 showed bilateral innervation of the medial appendix (MA) (Fig. 6F) and the dorsomedial protocerebrum. The calyx is innervated by olfactory PNs, 19-22 of which are visualized by GH146-GAL4 (Fig. 6G) (Heimbeck et al., 1999). Their precise connectivity between antennal lobe glomeruli and calyx glomeruli was analyzed at single-cell level (Ramaekers et al., 2005; Masuda-Nakagawa et al., 2009).

From the two types of non-KC MBINs that we identified (Fig. $6 H, I$ ), a single neuron visualized by GH146-GAL4 had a basolateral cell body (BL neuron) and innervated specifically the pedunculus (Fig. $6 H$ ). Moreover, a neuron labeled by NP3128 and termed anterior paired basolateral (APBL) neuron because of its cell body position interconnected the ipsilateral and contralateral medial lobes (Fig. $6 I$ ). Interestingly, although our screen included nine lines that express GAL4 in the adult dorsal paired median (DPM) neuron (Waddell et al., 2000; Tanaka et al., 2008), none of them revealed any DPM equivalent in the larva.

\section{Discussion}

The mushroom bodies, multifunctional centers of insect brains

One of the proposed functions of insect $\mathrm{MBs}$ is to act as an integration center for multiple sensory modalities. For example, recordings from efferent neurons in the cockroach MBs demonstrate that the MBs integrate, in a context-specific manner, the dominant olfactory input with visual, tactile, and acoustic information (Strausfeld et al., 2003). In Drosophila, MBs were reported to be involved in many tasks, such as locomotor control, sleep, complex forms of visual learning, courtship conditioning, place memory, context-dependent association, and experience-dependent nonassociative osmotactic responses (for a detailed description see Tanaka et al., 2008). In many insects, including adult Drosophila, MBs are also known to function as centers for olfactory learning and memory (Heisenberg, 2003; McGuire et al., 2005; Keene and Waddell, 2007), while

$\mathrm{vl}$, Vertical lobe of the mb; sp, spur; la, lateral appendix; $\mathrm{ml}$, medial lobe of the mb; ma, medial appendix; al, antennal lobe; ca, calyx; act, antennocerebral tract; ped, pedunculus. 

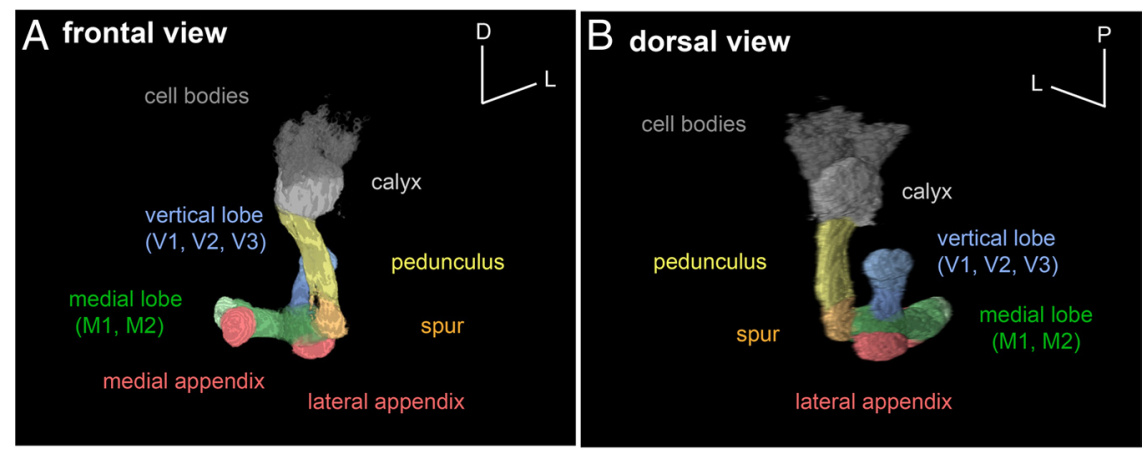

C embryonic-born y neurons

D larval vertical lobe

$E$ larval-born $\alpha^{\prime} / \beta^{\prime}$ neurons larval-born y neurons
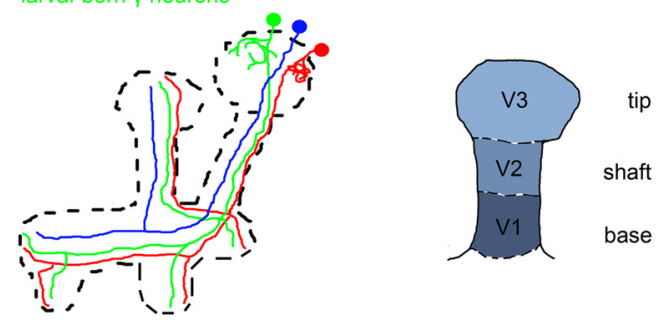

medial

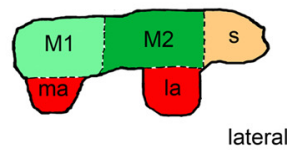

Figure 7. Model of the larval mushroom body. $A, B, 3$ reconstruction of the $M B$ of a third instar larva in frontal and dorsal view (available online as supplemental Movie $\mathrm{S1}$, available at www.jneurosci.org as supplemental material). $C$, The larval MBs comprise three types of KCs: embryonic-born $\gamma$ neurons, larval-born $\gamma$ neurons, and larval-born $\alpha^{\prime} / \beta^{\prime}$ neurons. $\boldsymbol{D}, \boldsymbol{E}$, Organization of the larval vertical and medial lobe. Apart from the calyx and pedunculus, eight different $M B$ subdomains are defined by the innervation of MBENs and non-KC MBINs: V3 (tip of vertical lobe), V2 (shaft of vertical lobe), V1 (base of vertical lobe), M1 (medial part of the medial lobe), M2 (lateral part of the medial lobe), spur (s), medial appendix (ma), and lateral appendix (la).

not being essential for certain experience-independent olfactoryrelated behaviors (de Belle and Heisenberg, 1994; Heimbeck et al., 2001; Kido and Ito, 2002; Wang et al., 2003).

\section{Larval olfactory learning relies on the mushroom bodies}

For Drosophila larvae, a number of arguments from published data and our own results (Figs. 1, 3) imply the necessity and sufficiency of the larval MB for olfactory learning and memory: (1) Classical learning mutants like dunce and rutabaga are impaired in larval appetitive (Honjo and Furukubo-Tokunaga, 2005, 2009) and aversive olfactory learning (Aceves-Piña and Quinn, 1979; Honjo and Furukubo-Tokunaga, 2009). As their gene products are highly enriched in the MBs, cAMP-pathwaydependent molecular coincidence detection of odor and reinforcement signaling in this brain structure was suggested (Crittenden et al., 1998). (2) The structural mutant mushroom body miniature is impaired in larval odor-electric shock learning (Heisenberg et al., 1985). (3) Blocking synaptic output via shibi$r e^{t s}$ using the MB-specific driver lines 201y and OK301 (Honjo and Furukubo-Tokunaga, 2005) or 201y and NP1131 (this study, Fig. 3) blocks larval appetitive and aversive learning (Honjo and Furukubo-Tokunaga, 2009). Specifically, the latter authors showed that output from chemical synapses of the MBs is required at test, but is dispensable during training to support normal appetitive and aversive memory. (4) Larvae of the rover allele of the foraging gene show higher initial scores for olfactory learning than sitter larvae (Kaun et al., 2007). foraging codes for protein kinase $G$, which displays low activity in sitter and high activity in rover variants (Osborne et al., 1997). Interestingly, the learning phenotype in sitters can be rescued to rover levels by boosting expression of the protein kinase $G$ in the MBs via the driver strains 201Y, H24, and c739 (Kaun et al., 2007). (5) Rein- forcement signaling by dopaminergic and octopaminergic neurons onto the MBs is likely to be necessary during training for aversive and appetitive olfactory learning (Honjo and Furukubo-Tokunaga, 2009; Selcho et al., 2009). Together these data strongly suggest that the larval MBs harbor an olfactory memory trace, similar to the role proposed for its adult counterpart (Heisenberg, 2003; Gerber et al., 2004; McGuire et al., 2005; Keene and Waddell, 2007).

\section{Synaptic connectivity defines subdomains of the larval mushroom body}

Based on the innervation patterns of MBENs and non-KC MBINs, we define at least 10 anatomical subdomains in MBs of third instar larvae (Fig. 7): calyx (MB-C), pedunculus (MB-P1; perhaps consisting of more than one subregion), spur (MB$\mathrm{S})$, vertical lobe comprising three subdomains (MB-V1, MB-V2, MB-V3), medial lobe with at least two subdomains (MBM1, MB-M2), lateral appendix (MB-LA), and medial appendix (MB-MA).

The larval olfactory pathway was proposed as an elementary olfactory model system, based on its strongly reduced nonredundant cellular organization but similar design as in adult insects (Vosshall and Stocker, 2007). Here we show that similarity with the adult stage also refers to the subdomain organization of the larval MBs. Tanaka et al. (2008) have shown that the adult vertical lobes consist of at least two lobes $\left(\alpha\right.$ and $\alpha^{\prime}$ ), each of which is partitioned by MBENs into three subdomains. The larval vertical lobe consists of only one lobe, which is however also divided into three subdomains (Fig. 7D). Likewise, both the adult $\gamma$ lobe and the larval medial lobe can be divided by MBEN innervation into five subdomains (Tanaka et al., 2008) (Fig. $7 E$ ). Yet, the adult medial lobes possess two more lobes, $\beta$ and $\beta^{\prime}$, each divisible into two subdomains by MBENs (Tanaka et al., 2008). Therefore, the adult lobes were suggested to consist of at least 15 subdomains, whereas the larval MB lobes, according to our data, comprise 10 subdomains. And recent data even functionally suggests an organization of the adult MB into different subunits involved in integrating the state of hunger and appetitive memory (Krashes et al., 2009), odor and electric shock sensation as well as aversive reinforcement signaling (Claridge-Chang et al., 2009; Mao and Davis, 2009). Obviously however, adult MB lobes are substantially more complex than their larval counterparts.

\section{Role of embryonic- and larval-born mushroom body Kenyon} cells in larval olfactory learning

During a first phase of proliferation, the four $\mathrm{MB}$ Nbs give rise to a total of $\sim 250$ embryonic-born functional KCs (Technau and Heisenberg, 1982; Ito and Hotta, 1992). The MB Nbs continue to proliferate throughout larval life. They give rise to $\gamma$ type KCs at earlier stages and $\alpha^{\prime} / \beta^{\prime}$ type KCs from the mid-third larval instar (Lee et al., 1999), generating in total $\sim 2000$ additional KCs (Technau and Heisenberg, 1982).

Here show that first instar larvae are able to establish odorsugar memory (Fig. $1 A$ ) and in addition that second and third 
instar larvae deprived of larval-born KCs can do so as well (Fig. $1 B, C)$. These data support the classical study by Aceves-Piña and Quinn (1979), which reported that first instar larvae are able to form associations between an odor and electric shock. Thus, it is tempting to speculate that the neuronal circuits underlying larval olfactory learning at the level of the MBs are established during embryogenesis. This is supported by the general idea that neurons generated during larval life, called secondary neurons, do not terminally differentiate before metamorphosis; they form unbranched neurites, called cell body fibers, that terminate at the cortex-neuropil boundary (Hertweck, 1931; Dumstrei et al., 2003). Such developmental patterns were described in detail for PNs (Jefferis et al., 2004; Marin et al., 2005), the adult optic lobes that account for most of the growth during larval brain development (Nassif et al., 2003), as well as for KCs of the honeybee (Farris et al., 1999). According to this interpretation, additional KCs generated during larval life would remain nonfunctional in the larva but are crucial for proper adult MB function.

In contrast to this, larval-born $\gamma$ type KCs establish dendritic terminals in up to six larval calyx glomeruli while differentiating during larval life (Lee et al., 1999; Masuda-Nakagawa et al., 2005). Thus we will not exclude that these neurons may participate in olfactory tasks that we have not addressed in our experiments.

However, the small number of only $\sim 250$ embryonic-born KCs involved in larval appetitive olfactory learning (Figs. 1-3) allow for analyzing how different odor memories are represented at the level of KC types or even single KCs. Remarkably, block of synaptic output in a set of $\sim 50$ embryonic-born KCs labeled by MB247 had no significant effect on appetitive olfactory learning for a particular odor combination (Fig. 2C), whereas block of another 70 or 25 embryonic-born KCs (included in the $201 \mathrm{y}$ or NP1131 pattern, respectively) led to significantly reduced performance (Fig. $3 D, H$ ). Thus it is well possible that the appetitive character of a specific odor is stored in small sets of embryonicborn KCs or even in single cells, which do not overlap in the two lines. Alternatively, as the three lines label only $~ 30 \%$ (for 201y), $20 \%$ (for MB247), or 10\% (for NP1131) of the embryonic-born $\mathrm{KCs}$, odor-memories may reside in larger $\mathrm{KC}$ populations in a complex pattern that is not yet understood.

\section{Integration of newborn neurons into the existing mushroom body circuitry}

Is neuronal plasticity limited to synaptic remodeling or are changes in learning performance related to neurogenesis? In house crickets, it was shown that KC proliferation during adult life improves olfactory learning (Cayre et al., 2007). Furthermore, adult neurogenesis in the mammalian subventricular zone, which gives rise to new neurons migrating into the olfactory bulb, was suggested to play a role in olfactory learning (Zhao et al., 2008). Yet, since investigations in this field are still rather limited, it is a matter of debate whether neurogenesis is indeed an important mechanism for learning and memory.

Based on our HU-ablation data, we propose that larval appetitive olfactory learning depends on the existing embryonic-born MB circuits (see above); thus we are tempted to exclude a participation of $\mathrm{KC}$ neurogenesis for larval learning. Therefore this hypothesis can now be validated using genetic approaches to interfere with KC development while monitoring associative olfactory learning in more detail. For example, it would be interesting to know whether continuous integration of new neurons into existing memory circuits modifies, impairs, or strengthens preexisting memory information, as recently sug- gested for hippocampus-dependent associative fear memory in rats (Kitamura et al., 2009).

\section{References}

Aceves-Piña EO, Quinn WG (1979) Learning in normal and mutant Drosophila larvae. Science 206:93-96.

Amrein H, Axel R (1997) Genes expressed in neurons of adult male Drosophila. Cell 88:459-469.

Armstrong JD, de Belle JS, Wang Z, Kaiser K (1998) Metamorphosis of the mushroom bodies; large-scale rearrangements of the neural substrates for associative learning and memory in Drosophila. Learn Mem 5:102-114.

Aso Y, Grübel K, Busch S, Friedrich AB, Siwanowicz I, Tanimoto H (2009) The mushroom body of adult Drosophila characterized by GAL4 drivers. J Neurogenet 23:156-172.

Brand AH, Perrimon N (1993) Targeted gene expression as a means of altering cell fates and generating dominant phenotypes. Development 118:401-415.

Cayre M, Scotto-Lomassese S, Malaterre J, Strambi C, Strambi A (2007) Understanding the regulation and function of adult neurogenesis: contribution from an insect model, the house cricket. Chem Senses 32:385-395

Claridge-Chang A, Roorda RD, Vrontou E, Sjulson L, Li H, Hirsh J, Miesenböck G (2009) Writing memories with light-addressable reinforcement circuitry. Cell 139:405-415.

Connolly JB, Roberts IJ, Armstrong JD, Kaiser K, Forte M, Tully T, O’Kane CJ (1996) Associative learning disrupted by impaired Gs signaling in Drosophila mushroom bodies. Science 274:2104-2107.

Crittenden JR, Skoulakis EM, Han KA, Kalderon D, Davis RL (1998) Tripartite mushroom body architecture revealed by antigenic markers. Learn Mem 5:38-51.

de Belle JS, Heisenberg M (1994) Associative odor learning in Drosophila abolished by chemical ablation of mushroom bodies. Science 263:692-695.

Duffy JB (2002) GAL4 system in Drosophila: a fly geneticist's Swiss army knife. Genesis 34:1-15.

Dumstrei K, Wang F, Nassif C, Hartenstein V (2003) Early development of the Drosophila brain: V. Pattern of postembryonic neuronal lineages expressing DE-cadherin. J Comp Neurol 455:451-462.

Farris SM, Robinson GE, Davis RL, Fahrbach SE (1999) Larval and pupal development of the mushroom bodies in the honey bee, Apis mellifera. J Comp Neurol 414:97-113.

Fishilevich E, Domingos AI, Asahina K, Naef F, Vosshall LB, Louis M (2005) Chemotaxis behavior mediated by single larval olfactory neurons in Drosophila. Curr Biol 15:2086-2096.

Gerber B, Hendel T (2006) Outcome expectations drive learned behaviour in larval Drosophila. Proc Biol Sci 273:2965-2968.

Gerber B, Stocker RF (2007) The Drosophila larva as a model for studying chemosensation and chemosensory learning: a review. Chem Senses 32:65-89.

Gerber B, Tanimoto H, Heisenberg M (2004) An engram found? Evaluating the evidence from fruit flies. Curr Opin Neurobiol 14:737-744.

Gerber B, Stocker RF, Tanimura T, Thum AS (2009) Smelling, tasting, learning: Drosophila as a study case. Results Probl Cell Differ 47:139-185.

Hayashi S, Ito K, Sado Y, Taniguchi M, Akimoto A, Takeuchi H, Aigaki T, Matsuzaki F, Nakagoshi H, Tanimura T, Ueda R, Uemura T, Yoshihara M, Goto S (2002) GETDB, a database compiling expression patterns and molecular locations of a collection of Gal4 enhancer traps. Genesis 34:58-61.

Heimbeck G, Bugnon V, Gendre N, Häberlin C, Stocker RF (1999) Smell and taste perception in Drosophila melanogaster larva: toxin expression studies in chemosensory neurons. J Neurosci 19:6599-6609.

Heimbeck G, Bugnon V, Gendre N, Keller A, Stocker RF (2001) A central neural circuit for experience-independent olfactory and courtship behavior in Drosophila melanogaster. Proc Natl Acad Sci U S A 98:1533615341.

Heisenberg M (2003) Mushroom body memoir: from maps to models. Nat Rev Neurosci 4:266-275.

Heisenberg M, Borst A, Wagner S, Byers D (1985) Drosophila mushroom body mutants are deficient in olfactory learning. J Neurogenet 2:1-30.

Hendel T, Michels B, Neuser K, Schipanski A, Kaun K, Sokolowski MB, Marohn F, Michel R, Heisenberg M, Gerber B (2005) The carrot, not the stick: appetitive rather than aversive gustatory stimuli support associative 
olfactory learning in individually assayed Drosophila larvae. J Comp Physiol A Neuroethol Sens Neural Behav Physiol 191:265-279.

Hertweck H (1931) Anatomie und Variabilitaet des Nervensystems und der Sinnesorgane von Drosophila melanogaster (Meigen). Z Wiss Zool 139:559-663.

Honjo K, Furukubo-Tokunaga K (2005) Induction of cAMP response element-binding protein-dependent medium-term memory by appetitive gustatory reinforcement in Drosophila larvae. J Neurosci 25:7905-7913.

Honjo K, Furukubo-Tokunaga K (2009) Distinctive neuronal networks and biochemical pathways for appetitive and aversive memory in Drosophila larvae. J Neurosci 29:852-862.

Ikeya T, Galic M, Belawat P, Nairz K, Hafen E (2002) Nutrient-dependent expression of insulin-like peptides from neuroendocrine cells in the CNS contributes to growth regulation in Drosophila. Curr Biol 12:1293-1300.

Ito K, Hotta Y (1992) Proliferation pattern of postembryonic neuroblasts in the brain of Drosophila melanogaster. Dev Biol 149:134-148.

Ito K, Suzuki K, Estes P, Ramaswami M, Yamamoto D, Strausfeld NJ (1998) The organization of extrinsic neurons and their implications in the functional roles of the mushroom bodies in Drosophila melanogaster Meigen. Learn Mem 5:52-77.

Iyengar BG, Chou CJ, Sharma A, Atwood HL (2006) Modular neuropile organization in the Drosophila larval brain facilitates identification and mapping of central neurons. J Comp Neurol 499:583-602.

Jefferis GS, Vyas RM, Berdnik D, Ramaekers A, Stocker RF, Tanaka NK, Ito K, Luo L (2004) Developmental origin of wiring specificity in the olfactory system of Drosophila. Development 131:117-130.

Kaun KR, Hendel T, Gerber B, Sokolowski MB (2007) Natural variation in Drosophila larval reward learning and memory due to a cGMP-dependent protein kinase. Learn Mem 14:342-349.

Keene AC, Waddell S (2007) Drosophila olfactory memory: single genes to complex neural circuits. Nat Rev Neurosci 8:341-354.

Keleman K, Krüttner S, Alenius M, Dickson BJ (2007) Function of the Drosophila CPEB protein Orb2 in long-term courtship memory. Nat Neurosci 10:1587-1593.

Kido A, Ito K (2002) Mushroom bodies are not required for courtship behavior by normal and sexually mosaic Drosophila. J Neurobiol 52:302-311.

Kitamoto T (2001) Conditional modification of behavior in Drosophila by targeted expression of a temperature-sensitive shibire allele in defined neurons. J Neurobiol 47:81-92.

Kitamura T, Saitoh Y, Takashima N, Murayama A, Niibori Y, Ageta H, Sekiguchi M, Sugiyama H, Inokuchi K (2009) Adult neurogenesis modulates the hippocampus-dependent period of associative fear memory. Cell 139:814-827.

Koushika SP, Lisbin MJ, White K (1996) ELAV, a Drosophila neuronspecific protein, mediates the generation of an alternatively spliced neural protein isoform. Curr Biol 6:1634-1641.

Kraft R, Levine RB, Restifo LL (1998) The steroid hormone 20hydroxyecdysone enhances neurite growth of Drosophila mushroom body neurons isolated during metamorphosis. J Neurosci 18:8886-8899.

Krashes MJ, Keene AC, Leung B, Armstrong JD, Waddell S (2007) Sequential use of mushroom body neuron subsets during Drosophila odor memory processing. Neuron 53:103-115.

Krashes MJ, DasGupta S, Vreede A, White B, Armstrong JD, Waddell S (2009) A neural circuit mechanism integrating motivational state with memory expression in Drosophila. Cell 139:416-427.

Kurusu M, Awasaki T, Masuda-Nakagawa LM, Kawauchi H, Ito K, Furukubo-Tokunaga K (2002) Embryonic and larval development of the Drosophila mushroom bodies: concentric layer subdivisions and the role of fasciclin II. Development 129:409-419.

Lee T, Lee A, Luo L (1999) Development of the Drosophila mushroom bodies: sequential generation of three distinct types of neurons from a neuroblast. Development 126:4065-4076.

Leiss F, Groh C, Butcher NJ, Meinertzhagen IA, Tavosanis G (2009) Synaptic organization in the adult Drosophila mushroom body calyx. J Comp Neurol 517:808-824.

Manoli DS, Foss M, Villella A, Taylor BJ, Hall JC, Baker BS (2005) Malespecific fruitless specifies the neural substrates of Drosophila courtship behaviour. Nature 436:395-400.

Mao Z, Davis RL (2009) Eight different types of dopaminergic neurons innervate the Drosophila mushroom body neuropil: anatomical and physiological heterogeneity. Front Neural Circuits 3:5.
Marin EC, Watts RJ, Tanaka NK, Ito K, Luo L (2005) Developmentally programmed remodeling of the Drosophila olfactory circuit. Development 132:725-737.

Masuda-Nakagawa LM, Tanaka NK, O'Kane CJ (2005) Stereotypic and random patterns of connectivity in the larval mushroom body calyx of Drosophila. Proc Natl Acad Sci U S A 102:19027-19032.

Masuda-Nakagawa LM, Gendre N, O’Kane CJ, Stocker RF (2009) Localized olfactory representation in mushroom bodies of Drosophila larvae. Proc Natl Acad Sci U S A 106:10314-10319.

McBride SM, Giuliani G, Choi C, Krause P, Correale D, Watson K, Baker G, Siwicki KK (1999) Mushroom body ablation impairs short-term memory and long-term memory of courtship conditioning in Drosophila melanogaster. Neuron 24:967-977.

McGuire SE, Le PT, Davis RL (2001) The role of Drosophila mushroom body signaling in olfactory memory. Science 293:1330-1333.

McGuire SE, Deshazer M, Davis RL (2005) Thirty years of olfactory learning and memory research in Drosophila melanogaster. Prog Neurobiol 76:328-347.

Menzel R, Leboulle G, Eisenhardt D (2006) Small brains, bright minds. Cell 124:237-239.

Michels B, Diegelmann S, Tanimoto H, Schwenkert I, Buchner E, Gerber B (2005) A role for Synapsin in associative learning: the Drosophila larva as a study case. Learn Mem 12:224-231.

Moreau-Fauvarque C, Taillebourg E, Boissoneau E, Mesnard J, Dura JM (1998) The receptor tyrosine kinase gene linotte is required for neuronal pathway selection in the Drosophila mushroom bodies. Mech Dev 78:47-61.

Nassif C, Noveen A, Hartenstein V (2003) Early development of the Drosophila brain: III. The pattern of neuropile founder tracts during the larval period. J Comp Neurol 455:417-434.

O’Dell KM, Armstrong JD, Yang MY, Kaiser K (1995) Functional dissection of the Drosophila mushroom bodies by selective feminization of genetically defined subcompartments. Neuron 15:55-61.

Osborne KA, Robichon A, Burgess E, Butland S, Shaw RA, Coulthard A, Pereira HS, Greenspan RJ, Sokolowski MB (1997) Natural behavior polymorphism due to a cGMP-dependent protein kinase of Drosophila. Science 277:834-836.

Pascual A, Préat T (2001) Localization of long-term memory within the Drosophila mushroom body. Science 294:1115-1117.

Ramaekers A, Magnenat E, Marin EC, Gendre N, Jefferis GS, Luo L, Stocker RF (2005) Glomerular maps without cellular redundancy at successive levels of the Drosophila larval olfactory circuit. Curr Biol 15:982-992.

Riemensperger T, Völler T, Stock P, Buchner E, Fiala A (2005) Punishment prediction by dopaminergic neurons in Drosophila. Curr Biol 15:1953-1960.

Scherer S, Stocker RF, Gerber B (2003) Olfactory learning in individually assayed Drosophila larvae. Learn Mem 10:217-225.

Schroll C, Riemensperger T, Bucher D, Ehmer J, Völler T, Erbguth K, Gerber B, Hendel T, Nagel G, Buchner E, Fiala A (2006) Light-induced activation of distinct modulatory neurons triggers appetitive or aversive learning in Drosophila larvae. Curr Biol 16:1741-1747.

Schwaerzel M, Monastirioti M, Scholz H, Friggi-Grelin F, Birman S, Heisenberg M (2003) Dopamine and octopamine differentiate between aversive and appetitive olfactory memories in Drosophila. J Neurosci 23:10495-10502.

Selcho M, Pauls D, Han KA, Stocker RF, Thum AS (2009) The role of dopamine in Drosophila larval classical olfactory conditioning. PLoS One 4:e5897.

Stocker RF, Heimbeck G, Gendre N, de Belle JS (1997) Neuroblast ablation in Drosophila P[GAL4] lines reveals origins of olfactory interneurons. J Neurobiol 32:443-456.

Strausfeld NJ, Sinakevitch I, Vilinsky I (2003) The mushroom bodies of Drosophila melanogaster: an immunocytological and golgi study of Kenyon cell organization in the calyces and lobes. Microsc Res Tech 62:151-169.

Tanaka NK, Tanimoto H, Ito K (2008) Neuronal assemblies of the Drosophila mushroom body. J Comp Neurol 508:711-755.

Technau G, Heisenberg M (1982) Neural reorganization during metamorphosis of the corpora pedunculata in Drosophila melanogaster. Nature 295:405-407.

Tettamanti M, Armstrong JD, Endo K, Yang MY, Furukubo-Tokunaga K, Kaiser K, Reichert H (1997) Early development of the Drosophila mush- 
room bodies, brain centres for associative learning and memory. Dev Genes Evol 207:242-252.

Truman JW, Bate M (1988) Spatial and temporal patterns of neurogenesis in the central nervous system of Drosophila melanogaster. Dev Biol 125:145-157.

Vosshall LB, Stocker RF (2007) Molecular architecture of smell and taste in Drosophila. Annu Rev Neurosci 30:505-533.

Waddell S, Armstrong JD, Kitamoto T, Kaiser K, Quinn WG (2000) The amnesiac gene product is expressed in two neurons in the Drosophila brain that are critical for memory. Cell 103:805-813.

Wang J, Ma X, Yang JS, Zheng X, Zugates CT, Lee CH, Lee T (2004) Transmembrane/juxtamembrane domain-dependent Dscam distribution and function during mushroom body neuronal morphogenesis. Neuron 43:663-672.

Wang Y, Chiang AS, Xia S, Kitamoto T, Tully T, Zhong Y (2003) Blockade of neurotransmission in Drosophila mushroom bodies impairs odor attraction, but not repulsion. Curr Biol 13:1900-1904.

Wong AM, Wang JW, Axel R (2002) Spatial representation of the glomerular map in the Drosophila protocerebrum. Cell 109:229-241.

Yang MY, Armstrong JD, Vilinsky I, Strausfeld NJ, Kaiser K (1995) Subdivision of the Drosophila mushroom bodies by enhancer-trap expression patterns. Neuron 15:45-54.

Yu D, Keene AC, Srivatsan A, Waddell S, Davis RL (2005) Drosophila DPM neurons form a delayed and branch-specific memory trace after olfactory classical conditioning. Cell 123:945-957.

Yu D, Akalal DB, Davis RL (2006) Drosophila alpha/beta mushroom body neurons form a branch-specific, long-term cellular memory trace after spaced olfactory conditioning. Neuron 52:845-855.

Zhao C, Deng W, Gage FH (2008) Mechanisms and functional implications of adult neurogenesis. Cell 132:645-660. 